\title{
Divagaciones en torno a la imagen del agujero. La Transición en la escritura del cuerpo de Marta Sanz
}

Ros Ferrer, Violeta

Universitat de València, España

violeta.ros@uv.es

Cita sugerida: Ros Ferrer, V.(2018).Divagaciones en torno a la imagen del agujero. La Transición en la escritura del cuerpo de Marta Sanz. En C. Somolinos Molina (ed.), "Escrituras del cuerpo: Marta Sanz". Olivar, 18 (27), e024. https://doi.org/10.24215/18524478e024

cc)(-) Esta obra está bajo licencia Creative Commons Atribución-NoComercial-CompartirIgual 4.0 Internacional http://creativecommons.org/licenses/by-nc-sa/4.0/deed.es_AR 


\title{
Divagaciones en torno a la imagen del agujero. La Transición en la escritura del cuerpo de Marta Sanz
}

\author{
Meanderings around the image of the hole. The Transition in the Scripts of the Body of \\ Violeta Ros Ferrer \\ Universitat de València, España \\ violeta.ros@uv.es
}

\section{RESUMEN:}

El presente artículo se propone indagar acerca de la escritura del cuerpo femenino en la obra de la escritora Marta Sanz, a propósito de la relectura de la Transición española que contienen buena parte de sus novelas. Para ello, partiremos del análisis de la metáfora del agujero en varios de los textos de la autora. Este trabajo busca llamar la atención sobre la crítica a la evolución de las formas de violencia y de control ejercidas sobre el cuerpo femenino que contiene la obra de Marta Sanz, a partir de los textos Los mejores tiempos (2001), La lección de anatomía (2008), Daniela Astor y la caja negra (2013) y Éramos mujeres jóvenes. Una educación sentimental de la Transición española (2016).

Palabras Clave: Narrativa española contemporánea, Marta Sanz, Transición, Escritura del cuerpo.

\section{Abstract:}

This paper approaches the writing of the female body in the literary work of Marta Sanz, specifically regarding to the representation of the Transition to democracy which most of her work contains. As a metaphoric tool, we will analize the image of the hole, which appears in a significant part of Sanz's work related to this matter. This paper aims to discuss the evolution in the ways of violence and control upon the female body which underlie most of the fiction and essays by this writer. With this purpose, we will discuss Los mejores tiempos (2001), La lección de anatomía (2008), Daniela Astor y la caja negra (2013) and Éramos mujeres jóvenes. Una educación sentimental de la Transición española (2016).

KEYWORDS: Spanish Contemporary Fiction, Marta Sanz, Transition, Female body.

\section{1- Introducción: agujeros, CUERPo y Transición en la escritura de Marta SANZ}

Ayudé a mi abuela Juana a ducharse. Para ella, todo lo que estaba entre las piernas, hacia delante y hacia detrás, se llamaba culo. Me giré, dándole intimidad para que se lo lavase. Entonces dijo, con aquella franqueza cómica con la que trataba los temas sexuales: "De tanto tener niños, ya no tengo agujeros separados. Creo que tengo un solo hoyo grande por el que sale todo junto. Que yo no sé muy bien lo que hay ahí, porque nunca me lo he visto". Imaginaba a mi abuela, detrás de mí, con un pozo insondable entre las piernas. Ese pozo era, en realidad, una laguna de represión y desconocimiento. Mi abuela me dijo, en alguna ocasión, que ella "se lo pasaba muy bien" con mi abuelo. Aun así, muchos puntos de su vida se adscriben a la norma social de la época. El cuerpo como ente impuro, maldecido por las palabras de la Iglesia, la mirada de Cristo y de la sociedad siempre presentes, la mano que aparta la del novio, la virginidad, la sangre y la amenaza de pecado constante, todo ello confluyendo en ese agujero de misterio. (Urraca, 2016).

El texto citado procede de un artículo publicado en prensa, que lleva por título "Hablamos con varias abuelas sobre cómo era su vida sexual". A pesar del marcado carácter pop del texto completo -que sin duda responde a su naturaleza periodística-, su planteamiento es, en sí mismo, sintomático y subversivo. Es sintomático porque aparece en un momento de revalorización pública del feminismo y, en especial, de todo lo que tiene que ver con la construcción discursiva de una emancipación sexual del cuerpo femenino siempre en construcción y siempre en revisión que, en el caso español, cuenta con una serie de lagunas adicionales que constituyen una herencia directa de cuatro décadas de franquismo. Y es subversivo porque, en este contexto, trae a la esfera de lo público lo que ni siquiera es frecuente encontrar en el espacio de lo privado: mujeres 
que han nacido, vivido y se han reproducido bajo la atenta vigilancia del régimen franquista y que hablan, no solamente sobre su vida sexual, sino también sobre sus cuerpos, sus fluidos y su relación con lo erótico.

La referencia a ese hoyo, a ese insondable pozo que Urraca se imagina entre las piernas de su abuela Juana como una laguna de represión y de desconocimiento, como un agujero de misterio, cobra en este contexto toda su relevancia. La imagen del agujero aparece aquí como un pretexto para hablar del cuerpo femenino como el espacio de inscripción de un tipo de violencia que tiene una dimensión cultural y una dimensión política.

Nos interesa aquí ese segundo tipo de violencia: la ejercida de forma programática sobre el cuerpo de la mujer primero por parte del régimen franquista a través de mecanismos de orden físico y simbólico, y de cómo esa forma de violencia ha pervivido después, de otros modos, en el presente democrático y en el contexto neoliberal. En esta evolución de las violencias sobre los cuerpos, la Transición se configura como un momento clave desde el que observar la naturaleza de estas mutaciones en las formas de control biopolítico, cuya crítica es uno de los ejes más importantes tanto de la narrativa como de la producción ensayística de Marta Sanz, a la que trataremos de acercarnos en este trabajo.

Podemos trazar una relación clara y directa entre el tragicómico lamento de Juana al lavarse ante su nieta y las divagaciones en torno a la imagen del agujero que subyacen en la escritura del cuerpo de Marta Sanz. Una es consciente de las implicaciones que conlleva asociar la imagen del agujero a las narrativas del cuerpo femenino, sobre todo porque se trata de una imagen que, leída desde Freud y, sobre todo, desde Lacan, podría quedar vinculada instantáneamente a la mujer como el territorio de la falta y a su cuerpo como el escenario más evidente en el que esa falta tiene lugar ${ }^{1}$. Por este motivo, no quisiéramos abrir la reflexión que aquí nos convoca sin antes puntualizar el sentido con el que traemos a nuestro trabajo la imagen del agujero \#o de los agujeros\# en relación con la construcción de su relato acerca del cuerpo femenino y el modo en que el conjunto de estos dos motivos -cuerpo y agujero- implica, a su vez, un acto de relectura de la Transición española como un locus fundacional del presente que va a atravesar buena parte de la obra de la autora.

Por un lado, la imagen del agujero es una metáfora que permite explicar con gran plasticidad lo que viene ocurriendo en relación con el modo en que la Transición, como periodo histórico, está siendo reconstruido desde el presente. Al margen de la evidente distancia ideológica que encontramos entre las distintas posiciones desde la que se narra la Transición, lo que tienen en común buena parte de estos relatos es una estructura cerrada: una voluntad de fijar el sentido de la Transición; de clausurar con relatos que dan por buena y definitiva una verdad histórica determinada, anulando la posibilidad de que otras verdades que habían sido taponadas emerjan del fondo de ese agujero discursivo o busquen reconstruirse desde el presente. En este sentido, lo que encontramos en la producción literaria y ensayística de Marta Sanz es un gesto que parece apuntar hacia una dirección opuesta: la de dejar al descubierto ese agujero, e ir bordeándolo con el lenguaje; un lenguaje cuya profusión no parece buscar taponar ese agujero fundacional del presente democrático, sino más bien lo contrario: abrirlo en canal para recuperar de él nuevos sentidos. Y este gesto intelectual y político pasa, en la narrativa de Marta Sanz, en buena medida por una escritura del cuerpo: del cuerpo femenino, del cuerpo agujereado.

En esa evolución de las violencias sobre los cuerpos femeninos que abordaremos con este trabajo, la Transición se configura como un momento clave en las mutaciones de las formas de control biopolítico, cuya crítica es uno de los ejes más importantes tanto de la narrativa como de la producción ensayística de nuestra autora. Puesto que nos ocuparemos, en las páginas que siguen, de esa intersección entre cuerpo y Transición, proponemos nuestro estudio a partir del análisis de dos de las novelas de Sanz \#Daniela Astory la caja negra (2013), La lección de anatomía (2014 [2008])\# y mencionaremos parcialmente algunos aspectos de una tercera\#Los mejores tiempos (2001)\#. La lectura, desde esta perspectiva, de estas tres novelas sería posteriormente enmarcada por un último trabajo publicado por la autora ya en clave de ensayo bajo el título Éramos mujeres jóvenes. Una educación sentimental de la Transición española (2016), al que solamente nos acercaremos brevemente. Abordaremos el conjunto de estos cuatro textos en un orden inverso al que fueron publicados, es decir, del más reciente al más temprano. 


\section{2- LA TEORÍA DE LOS CUERPOS AGUJEREADOS}

En su teoría de los cuerpos agujereados, Marta Segarra parte de un primer intento de definir qué es un agujero:

El agujero tiene un papel protagonista en mitos fundadores de infinidad de culturas, pero también en teorías científicas, tanto en el campo de la biología como en la medicina, la geografía, la astronomía y un largo etcétera, además de construir un elemento esencial en nuestro aprendizaje vital, desde las incipientes sensaciones del bebé, según aseguran los psicoanalistas.

Los orificios anatómicos son, en efecto, los elementos en torno a los cuales se organiza la experiencia y el progresivo autoconocimiento del cuerpo desde las primeras semanas de vida, y seguirán ejerciendo una suprema fascinación a lo largo de toda nuestra existencia. De ahí esta teoría de los cuerpos agujereados, cuyo postulado esencial es el siguiente: todo agujero físico e imaginario [...] se relaciona con los orificios del cuerpo humano, lo cual se refleja en los discursos científicos, pero también en los relatos míticos y en la actual cultura popular, entre otros. (Segarra, 2014: 10)

La teoría que nos propone Segarra parte de una aproximación etimológica al término agujero que, a partir de la materialidad de la palabra, pueden establecerse con una dimensión más abstracta de la misma. De este modo, la aproximación etimológica que Segarra propone a partir de varios idiomas, lo irá dotando de una serie de constelaciones semánticas por la que constata los vínculos que el término agujero presenta con otros significantes aparentemente lejanos a este.

A partir de este trabajo etimológico, Segarra constata la vocación paradójica del término, cuyas raíces indoeuropeas lo relacionarían, en primer lugar, con las nociones opuestas de cielo e infierno a un mismo tiempo y en una misma raíz léxica ${ }^{2}$. En segundo lugar, a través de la versión francesa de la palabra agujero \#trou\#, Segarra explica cómo ya en la época medieval, el término se refería a la imagen de abertura en el cuerpo o cavidad en la tierra, que muy pronto adquirió un claro significado sexual, especialmente en relación con la anatomía femenina ${ }^{3}$. En relación con la etimología del término francés, Segarra lleva su constelación semántica un paso más allá, y destaca el vínculo que, a partir del siglo XIX, empieza a producirse en la lengua francesa entre las nociones de agujero y memoria, generando expresiones como trou de mémorie -agujero en la memoria-, especialmente útil para pensar sobre el caso que nos ocupa ${ }^{4}$.

De entre estos significantes, nos interesan especialmente los del cuerpo y la memoria. La imagen del agujero como un punto en el espacio que permite la fuga, como un significante que remite al cuerpo y a la sexualidad femenina y, en última instancia, como una horadación, interrupción o cortocircuito en el marco de un proceso de memoria, parece un enclave lingüístico sugerente desde el que abordar algunos de los textos de Marta Sanz, especialmente aquellos en los que el cruce entre la cuestión del cuerpo y la relectura de la Transición constituyen un motivo central.

\section{Cuerpos y Memoria}

La segunda cuestión consistiría en poner de relieve una lectura política de los cuerpos en su relación con los procesos de la memoria histórica en España. Cuerpo y memoria son, en definitiva, dos ejes que se cruzan necesariamente cuando hablamos de la memoria de la represión franquista, en sus diferentes formas y a lo largo de sus sucesivas etapas históricas.

En un texto titulado "Estigma y memoria de los jóvenes de la Transición" 5 , el historiador Pablo Sánchez León sugería una idea que, con el tiempo, ha ido convirtiéndose en un gesto repetido en los procesos abiertos en relación con la memoria de la represión durante la Guerra Civil, el franquismo, la Transición y sus continuidades, ya en periodo democrático. Esta idea consiste en la propuesta de un desplazamiento metonímico entre el sentido político de los cuerpos de los represaliados durante la Guerra Civil y primeros años del franquismo, y el "estigma" con el que cargaron muchos de los cuerpos jóvenes de la Transición -los signos de las llamadas "enfermedades sociales", como la sobredosis, enfermedades derivadas del consumo de drogas, suicidios, SIDA, etc. (Sánchez León, 2003: 168)-. Si bien en primer lugar se trata, evidentemente, 
de aquellos cuerpos que han permanecido apilados en las cunetas y fosas comunes sembradas a lo largo y ancho de todo el Estado español \#de nuevo, los agujeros\#, Sánchez León apunta, en segundo lugar, hacia los cuerpos de la cohorte generacional nacida a mediados de los años 50: una generación que, durante los años de Transición y postransición \#los ochenta y noventa\#, fue mermada por el consumo de drogas y por las enfermedades físicas y la marginación social que le suelen ir asociadas. Para Sánchez León, estos últimos son cuerpos que dieron a parar en hospitales y en cementerios, sin llegar a ser leídos ni reivindicados desde una dimensión política ${ }^{6}$.

Encontramos en la propuesta de Sánchez León un motivo que, en cierta medida, también será compartido por los textos narrativos de los que nos ocuparemos a continuación. Se trata de un motivo insoslayable en cualquier reflexión en torno a la memoria histórica y su herencia en nuestro país: los cuerpos asociados a los agujeros $^{7}$. Podemos entender en este sentido el desplazamiento metonímico por el que se incluyen otro tipo de cuerpos distinto a los que esperaríamos encontrar, en un principio, dentro del mausoleo de la memoria de la derrota. En esta dirección, Sánchez León propone una lectura de estos "cuerpos jóvenes estigmatizados" como el producto de una forma de represión en términos biopolíticos. Es precisamente en este punto donde aparece un elemento fundamental que va a resonar también en los textos de Marta Sanz, y que tiene que ver con la visibilización de los resortes y las consecuencias de las biopolíticas de transición sobre una parte del cuerpo social.

Tanto en un caso como en otro, transición no se refiere únicamenteal tránsito de un régimen dictatorial a otro democrático, sino también al proceso de tránsito social y económico que ocurre de forma paralela desde un modelo económico autárquico hacia un modelo económico de raíz liberal o capitalista: el llamado desarrollismo económico de los años sesenta como el estadio previo y necesario hacia la consolidación, ya en la década de los ochenta, del sistema económico neoliberal.

Desde esta perspectiva el trabajo en torno a las narrativas sobre el cuerpo femenino en tanto que dispositivo oblanco privilegiado del control biopolítico -primero del franquismo y después de la Transición- cobra una dimensión específica y sitúa los textos de Marta Sanz en un lugar central y poco explorado dentro del marco de la producción de los discursos críticos sobre la Transición en el campo literario actual.

\section{Los CUERPOS FEMENINOS EN LA TrANSICIÓN}

Para acercarnos desde esta perspectiva a la propuesta literaria de Sanz, resulta de gran interés abordar, en este punto, el trabajo de Aurora Morcillo (2016). La propuesta central del estudio de Morcillo consiste en una lectura historiográfica de la relación simbólica entre el cuerpo político y el cuerpo femenino como una alegoría de la nación a lo largo de las sucesivas etapas del franquismo. Con este propósito, Morcillo se detiene en el análisis de la utilización metafórica de las imágenes sexuadas de los cuerpos femeninos en los discursos políticos del régimen desde el periodo autárquico hasta la etapa desarrollista.

Morcillo analiza el modo en que durante el franquismo, al igual que ocurría en otros regímenes totalitarios como el nazismo alemán o el fascismo italiano, "el concepto de 'nación' se transmuta en la figura física de una 'mujer' con todas las cualidades que se le asocian: maternidad, vulnerabilidad, fertilidad...” (Morcillo, 2016: 7-8). Una transmutación que, ya en los años sesenta y con la progresiva implantación de una cultura de consumo - no únicamente en España, sino en el contexto del proceso de americanización de Europa durante la Guerra Fría- se fue desplazando hacia otro tipo de metáforas y significados, en los que la asociación de la imagen del cuerpo femenino a una serie de valores vinculados a un concepto muy determinado de la feminidad no dejó de ser una constante y no perdió -ni siquiera hoy lo ha hecho- su carácter prescriptivo ${ }^{8}$.

El trabajo de Morcillo señala dos aspectos importantes a la hora de entender esta evolución en el régimen de representación de los cuerpos femeninos bajo el franquismo. En primer lugar, Morcillo subraya el modo en que el régimen utilizó la sexualidad y el género como los dispositivos privilegiados de control sobre el 
cuerposocial, cuya finalidad fue definir y fijar las estructuras políticas y sociales de corte nacionalcatólico impuestas tras la Guerra Civil. El cuerpo femenino fue el principal destinatario del ejercicio de este control; un control que era ejercido principalmente por parte de la Iglesia y del Estado (sobre todo a través de las instituciones educativas), pero que también contaba con una cultura mediática dirigida específicamente al consumo femenino ${ }^{9}$, cuyo poderoso despliegue de artillería sentimental funcionaba, muy frecuentemente, como una cadena de transmisión de los valores del régimen. En segundolugar, Morcillo remarca la centralidad que fueron adquiriendo los propios intereses del sistema económico como un condicionante discursivo que resulta imprescindible tener en cuenta en las consideraciones sobre la circulación de las imágenes del cuerpo femenino en el imaginario cultural y nacional, así como su evolución a partir de la última etapa del franquismo y, especialmente, con el inicio del proceso de Transición ${ }^{10}$, donde concluye su trabajo.

Ambos aspectos serán muy importantes para entender lo que ocurrirá en los años de la Transición en relación con esa memoria de los cuerpos femeninos bajo el control de la represión franquista que no ha sido del todo contada y de la que nuestras abuelas y nuestras madres todavía son portadoras. Una memoria que, tal y como se esfuerzan en mostrar los textos de Sanz, llega a ser doble y contradictoria.

El trabajo de Morcillo presenta una lectura positiva de la influencia que ese proceso de transición de un modelo económico a otro iba a tener en la reconfiguración de los roles de género femeninos más tradicionales. No caeremos aquí en negar de forma tajante la lectura de Morcillo a este respecto. Sin embargo, antes que profundizar en esa lectura de signo positivo del proceso de emancipación que tiene lugar a través de la modificación en la mirada sobre el cuerpo femenino, elegimos situar nuestro trabajo en el gesto crítico que busca subrayar esas continuidades -las herencias y mutaciones perniciosas de una mirada estructuralmente patriarcal- ocurridas a partir de este momento 1978 en el que Morcillo concluye su estudio. Lo que encontramos en los textos de Marta Sanz que abordaremos a continuación es, precisamente, una propuesta de reconstrucción del discurso sobre el cuerpo femenino en la Transición distinta a la que nos ofrecen buena parte de los relatos sobre la época. La principal particularidad de estos textos consiste en que dicha reconstrucción se propone desde la herencia, las secuelas o los ecos que esos discursos sobre el cuerpo tienen en el presente.

\section{UNA APROXIMACIÓN A LOS TEXTOS}

\section{1. Éramos mujeres jóvenes. Una historia sentimental de la Transición: un marco de reflexión}

No resulta difícil, en este punto, pensar en un posible diálogo que podría establecerse entre el motivo central sobre el que se articula una de las ficciones que abordan la construcción discursiva de la identidad femenina de forma más temprana en el contexto de la narrativa española, El cuarto de atrás (1978), y la novela que, de forma más representativa, va a proponer una actualización de esta memoria específica de los cuerpos femeninos durante la Transición aparecida en los últimos años, Daniela Astory la caja negra. Tampoco resulta difícil, en este sentido, trazar un paralelismo entre Los usos amorosos de la posguerra española (Martín Gaite, 1987), el ensayo que en 1987 publicaba Carmen Martín Gaite nueve años después de la aparición de El cuarto de atrás y como una especie de cuenta pendiente que le había quedado a la autora con esta novela, y el ensayo que Marta Sanz publicaba a finales de 2016 en un evidente diálogo con sus dos novelas Daniela Astor y la caja negra y La lección de anatomia, titulado Éramos mujeres jóvenes. Una historia sentimental de la Transición (2016).

Éramos mujeres jóvenes. Una historia sentimental de la Transición funciona casi como una declaración de intenciones a posteriori que explicita buena parte de las preocupaciones y de los elementos centrales que podemos extraer de la lectura de los otros tres textos de Marta Sanz que comparten el cuerpo y la Transición 
como motivos centrales. Con ensayo también adquiere relevancia el marcado componente autobiográfico de la obra de la autora, que ya ha sido señalado por la crítica (Somolinos, 2016 y Vara, 2015) sobre todo en relación con las dos novelas que aquí nos interesan por el cruce evidente entre la narrativa en torno al cuerpo femenino y la relectura de la Transición como un cronotopo muy reconocible en la obra de la autora.

Volvamos ahora sobre las constelaciones semánticas en torno a la imagen del agujero que proponía Segarra para formular tres claves de lectura que aparecen asociadas a esta noción de Transición, y que vamos a encontrar de la mano en los textos en los que aquí nos centraremos.

\subsection{Daniela Astor y la caja negra: caja de pandora, agujero sin fondo}

La primera de estas constelaciones es la que vincularía la imagen del agujero a la de un recinto oscuro y cerrado; algo como, por ejemplo, una caja. En su indagación en torno a las representaciones culturales de esa imagen del agujero asociada al cuerpo femenino y su sexualidad, Segarra se remonta a la mitología clásica para encontrar el origen de muchos de los tópicos o motivos recurrentes que, incluso hoy en día, seguimos encontrando tematizados en la cultura popular en relación con la construcción de una serie de imaginarios en torno a la mujer como cuerpo sexuado ${ }^{11}$. En este punto, el desplazamiento de la imagen del agujero a la imagen de la caja cerrada, nos remite directamente a Daniela Astor y la caja negra.

Este es el texto de Sanz que más claramente se inserta en una línea crítica para con el imaginario transicional muy bien definida en el contexto de la narrativa española abierta especialmente a partir del año 2011, aunque evidentemente se trata de una línea que podríamos rastrear desde bastante atrás. El rasgo que distingue este texto de entre los que podríamos ubicar en esta línea narrativa es, precisamente, que se trata de una propuesta de revisión crítica de un relato hegemónico de la Transición que pasa por una voluntad expresa de desnaturalizar los discursos más celebratorios en torno a la producción social de roles de género en la España de la Transición y que afronta directamente lo que esos relatos han formulado como el mito del destape.

La imagen central sobre la que el propio texto llama la atención ya desde el título, la caja negra, funciona en este sentido como un elemento cohesionador de la doble trama de la que se compone su discurso: La caja negra es el documental sobre el destape que está rodando Catalina $\mathrm{H}$. Griñán en el tiempo narrativo presente y la caja negra es, también, una zona oscura de la memoria de la protagonista desdoblada; un receptáculo cerrado donde Cata/Daniela guarda la dolorosa historia que no ha sido contada y cuyos efectos se dejan sentir todavía en el presente.

La caja negra funciona, de este modo, como un agujero: como un receptáculo cerrado, oscuro, al que la luz no puede acceder, y cuyo contenido tiene que ver, precisamente, con la parte catastrófica poco o nada revisitada de la historia oficial. La mujer que, en plena fiesta democrática -la elección de la fecha es, en este sentido, muy significativa: 1978-, cumple una pena de cárcel de seis meses y un día por someterse a un aborto de forma voluntaria, sin justificarse en una supuesta locura o depresión, desvinculando su cuerpo, de Eormaiente y voluntaria, del valor de potencia demográfica ${ }^{12}$. Que el sistema asigna a todo cuerpo femenino por defecto.

Nosotros no podemos convertir esta historia en un silencio porque el silencio es un modo de subrayar las cosas, pero también de borrarlas. Yo sufrí con lo que no vi. Con lo que imaginé. Con las ondas. Con el paréntesis, la elipsis y las salpicaduras. [...] Un día de noviembre de 1978 a las ocho de la mañana dos policías llamaron al timbre. Presentaron un papel y se llevaron a mi madre. Entonces, en la comisaría y en el juzgado, entre uniformes oscuros y togas, empezaron los cuentos de dragones y espadas. El tiempo se hizo petróleo. Nos manchó la ropa. En mi memoria queda un ruido blanco: paisajes difusos, casi borrados completamente, del ir y venir de mi madre.

La catástrofe de noviembre de 1978 queda registrada en nuestra caja negra. Aún hoy sobrecogen los estragos de esa grabación. (Sanz, 2013: 240-242).

Del mismo modo que Catalina relee ese episodio de su infancia para comprender mejor, para tratar de entender desde la perspectiva adulta lo que desde la perspectiva infantil le resultó imposible, la novela propone 
el acto de relectura de la Transición como si fuera también el contenido de una caja negra; una caja negra recuperada un tiempo después, cuyo significado es de difícil acceso hoy, por haberse fosilizado, carbonizado, en un relato poco justo de algunos aspectos del largo, lento y difícil proceso de cambio político en España. La caja negra funciona en el texto, como metáfora, del mismo modo en que lo hace como objeto en la realidad: como un artefacto que guarda un secreto, una verdad codificada que precisa de un agente descodificador para revelar su contenido.

Cuando se trata de las zonas más oscuras de la Transición, este agente descodificador tiene que ver inevitablemente con una cuestión política, ya sea esta más o menos explícita. En el caso que nos ocupa, este acto de descodificación tiene que ver con un proceso de desenmascaramiento de ciertas lógicas discursivas cuyo blanco de poder es el cuerpo de la mujer. En este proceso de desenmascaramiento, el motivo del aborto funciona como un elemento central que abre un agujero en el tiempo, ya que se pone en el centro de la narración como una cuestión igualmente problemática en 1978 que en 2013, año en el que la novela era publicada y año también en el que se aprobaba en España una Ley del Aborto que retrocedía en los derechos adquiridos a este respecto a las leyes anteriores a $1983^{13}$.

Tanto el juego de las identidades narrativas (Cata - Daniela - Catalina H. Griñán) como el juego de perspectivas temporales que conforman los diferentes planos del relato (la infancia funciona como un primer plano del relato en el que se narra el episodio central de la ficción y la madurez aparece como un segundo plano, desde el que enuncia la docuficción) se configuran alrededor de dos motivos que comparten, en realidad, esa centralidad de la reflexión acerca de la proyección de las imágenes del cuerpo femenino: por un lado está la obsesiva mirada sobre la madre y, por otro, el trabajo de construcción y deconstrucción del relato del destape.

En este juego de perspectivas es, precisamente, donde podemos identificar las dos ideologías de género opuestas entre sí que circulan en ese cruce de miradas. A la instancia enunciativa de carácter normativo, que cobra una forma privilegiada en la imaginación preadolescente de Cata - una imaginación colonizada por los discursos e imágenes de lo femenino sacados de los programas de televisión, las revistas del corazón, el fantaterror o, incluso, de la precoz adivinación de los deseos y las expectativas de los pocos hombres que la rodean ${ }^{14}$ - se le opone el constante proceso de deconstrucción de ese discurso normativo a través del progresivo desenmascaramiento del relato del destape que encontramos en documental La caja negra, así como el relato del castigo -familiar, social y penal- que la madre recibe como consecuencia de su decisión de abortar. El choque de ambas ideologías es la clave que conforma el binomio Catalina/Daniela, y es también la causa del sufrimiento de buena parte de los personajes femeninos que aparecen a lo largo de toda la novela.

El pasaje en el que Cata y Angélica juegan a la gruta del monstruo (Sanz, 2013: 65-70) muestra con enorme claridad esta colonización salvaje del imaginario infantil de ambas niñas por parte de las imágenes recibidas en relación explícita con una sexualidad todavía incipiente. No obstante, una lectura más distanciada de este fragmento permite leer en él -más allá de la denuncia explícita de la influencia que ejerce la perversa colección de imágenes y conductas que nos brinda la cultura del destape en el aprendizaje de un determinado rol de género- una cierta liberación de la sexualidad de ambas niñas que hubiera sido muy difícil encontrar en las mujeres de la generación de Carmen Martín Gaite. De modo que el juego de la gruta del monstruo se opondría felizmente a ese pozo de desconocimiento del que nos hablaba el texto de Sabina Urraca.

\subsection{La lección de anatomía: autorretrato y cuerpo}

También partiendo de la imagen del agujero llegamos al cuerpo femenino, del que el agujero constituye el rasgo definitorio de su anatomía:

Uno de los orificios corporales más cargado de simbolismo y más propicio a fantasear con él es el sexo-agujero de las mujeres, puerta de entrada al mundo al nacer. Y aunque podríamos suponer que este debería poseer sólo connotaciones positivas, debido a su función sexual y reproductora, el psicoanálisis, la antropología y, más allá de estas disciplinas, la vida cotidiana de 
muchas personas nos demuestran que la realidad está lejos de confirmar esta suposición. El sexo femenino provoca fascinación y atracción en hombres y mujeres, sin duda, pero también miedo y rechazo. En este caso se asocia con frecuencia a imágenes inquietantes como la de un agujero o abismo sin fondo en el que se puede caer e incluso desaparecer: recordemos la secuencia que imita una película antigua en Hable con ella de Pedro Almodóvar (2002), donde el hombre menguante se introduce en la vagina de su novia y no vuelve a salir [...]. (Segarra, 2014: 61).

Señala Segarra la necesidad de neutralizar el carácter negativo de las representaciones culturales más tradicionales de la sexualidad femenina que ha sido representada históricamente desde una perspectiva negativa, sea como negación o sea como rechazo. Para Segarra, "toda exhibición del sexo femenino es fálica, es decir, significa un poder amenazador" (2014: 64). En este sentido, con la mención al sexo femenino, a esa idea del agujero que ponía ya en un primer plano el pequeño fragmento con el que abríamos este texto, no buscaba traer a colación la genitalidad femenina en su literalidad más radical, sino como una alusión metonímica -de nuevo, las metonimias- a la sexualidad femenina y, en especial, a lo que esta tiene de construcción cultural, discursiva e ideológica. El vínculo entre los textos Daniela Astor y la caja negra y La lección de anatomía es, en este sentido, evidente.

A pesar de compartir la preocupación central en torno a la representación del cuerpo femenino y la reivindicación del acto de conquista de un lenguaje propio que lo nombre, La lección de anatomía se sitúa, sin embargo, en unas coordenadas narrativas distintas. Si bien Daniela Astor y la caja negra se proponía desde el espacio de la ficción, La lección de anatomía se propone casi en términos pictóricos como un autorretrato, es decir, como una narración autobiográfica.

Para los críticos de arte, la definición del autorretrato como género pictórico presenta unas características muy específicas. Destaca, en esta definición, su carácter de "ficción performativa" que le atribuye al género Jaques Derrida (Segarra, 2014: 35), es decir, del autorretrato como un género que necesita del pacto con el espectador para conformarse como tal. Este es, precisamente, el paso que da La lección de anatomía con respecto a Daniela Astor y la caja negra, pero también con otras ficciones publicadas con anterioridad y con posterioridad, en las que los elementos autobiográficos son fácilmente detectables.

[...] Su identificación [la del autorretrato como tal] depende siempre de un referente externo a la obra en sí y de alguien que lo admita como tal. Por ello, el espectador pasa a formar parte del autorretrato y así, rompe con el solipsismo narcisista que solemos asociar con este género y con su carácter de exaltación de un individuo singular, introduciendo la pluralidad en esta singularidad. (Segarra, 2014: 33).

Resulta muy significativo cómo es justamente en este punto donde aparece la lectura política de La lección de anatomía, sobre todo si la entendemos como narración que, precisamente, se enuncia desde el relato en torno al propio cuerpo como el lugar en el que se inscribe "una historia y una geografía" individual pero también colectiva ${ }^{15}$. En la matriz de ese relato, la Transición se ve representada como un nudo de discursos, de normas y de acontecimientos más o menos significativos que se inscriben en ese cuerpo narrante. La Transición, como la materialización de un espacio-tiempo biográfico y político, constituye un elemento esencial en la conformación de ese sujeto femenino que busca tomar la palabra para construir un discurso alternativo a buena parte de los relatos heredados, tanto sobre el propio cuerpo \#biopolíticamente marcado, condicionado y regulado por una ideología de género establecida y dominante, que es evidentemente masculina\# como sobre la Transición como proceso histórico. En los textos se ve de forma clara cómo la Transición, en tanto que proceso de cambio político, social y cultural, ha condicionado las formas de vida que tanto La lección de anatomía como todos los textos de Marta Sanz buscan retratar con un claro componente generacional.

En este punto y en tanto que crónica de un tiempo, el diálogo entre Daniela Astor y la caja negra y La lección de anatomía se establece, como decíamos, de forma explícita. Si en Daniela Astor y la caja negra la denuncia de estos relatos heredados se hacía visible a partir del señalamiento de la contradicción existente entre toda una serie de discursos mitificadores en torno al proceso de liberación y emancipación sexual de la mujer durante los años del cambio político en España y la insuficiencia de este proceso en muchos aspectos, en La lección de 
anatomía este gesto de denuncia se construye a partir de un relato de vida que se articula en torno al cuerpo propio como el lugar físico -la geografía- en el que esas violencias se han ido inscribiendo a lo largo de los años. Este será, a nuestro entender, el gesto que busca ser formulado ya explícitamente con la publicación de ese último ensayo en el que, además de insistir en las herencias de ese proceso de disciplinamiento de los cuerpos femeninos, incide en el componente sentimental de ese disciplinamiento que lo es, en realidad, en cuerpo y alma, siguiendo las metáfora propuesta por Aurora Morcillo.

Volviendo de nuevo sobre el leitmotiv de la imagen del agujero, Segarra señala lo siguiente, esta vez en relación con el autorretrato:

[...] En el rostro, lo que más remite a lo humano, pero nos hunde también en lo inanimado a través de sus 'agujeros negros', son los ojos. El autorretrato se caracteriza precisamente desde sus orígenes, por dar protagonismo a la mirada del objeto y sujeto de la obra. Como afirma Pascal Bonafoux, pintarse a sí mismo es pintar el acto de ver o, más exactamente, de mirar y, por lo tanto, equivale a mirarse mirar. Ello es debido, en primer lugar, a la técnica clásica del autorretrato en pintura: el artista debe mirarse en un espejo para copiar sus propios rasgos, entre ellos sus propios ojos. (Segarra, 2014: 35 ).

Esta reflexión nos remite directamente al pasaje final, al cierre de La lección de anatomía. En esta escena final, el gesto del autorretrato narrado que se va gestando a lo largo de toda la novela cobra un carácter explícitamentepictórico. En ella la autora se dirige directamente a ese lector/espectador cómplice y escenifica abiertamente el acto de tomar el pincel y la palabra:

Cada palabra es un modo, más o menos honesto, de autorretratarse. Llevo mi honestidad hasta el impudor del desnudo. Mi autorretrato desnudo colgará de la sala de un museo. Alguien entrará y lo mirará y dejará de mirarlo. El contemplador dará vueltas alrededor de la sala, se detendrá frente a otras obras. De pronto algo le hará girar sobre sus talones para descubrir quién le persigue. Se fijará otra vez en mi desnudo. Reparará en mis ojos adormecidos. Caminará hacia la galería principal. Volverá de nuevo sobre sus pasos. Mirará por tercera vez y, como un niño que juega al escondite, procurará escamotear su cuerpo. Lo mire desde donde lo mire, desde el punto más recóndito o lateral de la sala, el contemplador no lo podrá evitar: soy yo la que lo está mirando. (Sanz, 2014: 357).

En este punto final del texto se hace evidente cómo el dispositivo del autorretrato lleva a la autora a ese mirarse mirar al que apuntaba Segarra. Se produce con este final un interesantísimo desplazamiento del lugar del cuerpo femenino como objeto -la principal denuncia que encontrábamos en el texto de Daniela Astor era, precisamente, la cosificación de los cuerpos femeninos por parte de los discursos del poder- al lugar del cuerpo femenino como sujeto, que mira mientras es mirado, que puede ser leído en diálogo con otro de los pasajes más representativos de la novela de 2013: la écfrasis del mítico desnudo de Marisol para la portada de la revista Interviu en 1976 (Touton, 2015 y Ros Ferrer, 2016).

De nuevo pensando desde la imagen del agujero, también encontramos en la apertura del texto La lección de anatomía la imagen del propio nacimiento en la reproducción del relato heredado del parto, otro motivo muy recurrente, según Segarra, en la historia del autorretrato femenino. En este sentido, el fragmento inicial que lleva por título "El día del parto de mi madre" (Sanz, 2014: 27-33) nos trae a la memoria uno de los autorretratos más conocidos de Frida Kahlo \#figura clave en la historia del autorretrato femenino y en cuya producción, recordemos, es central su particular mirada sobre del cuerpo propio como lugar de inscripción de su historia vital\#. Del mismo modo que el inicio de La lección de anatomía, este famoso autorretrato, titulado Mi nacimiento, nos pone delante de los ojos la imagen del parto como el momento fundacional del relato de vida, poniendo sobre la mesa, a su vez, una escritura que impregna de fluidos corporales la narración ya desde las primeras páginas del texto, y que constituye uno de los rasgos más reconocibles de la escritura del cuerpo tan reconocible en la obra de Marta Sanz. Tanto este relato del parto asociado con la maternidad, como la carnalidad del lenguaje con el que se dibuja esta imagen serán, pues, una constante en la escritura de los cuerpos que encontramos buena parte de los textos de la autora, cuya presencia será central en estas dos novelas. 


\subsection{Los mejores tiempos: infancia, agujeros y memoria}

Volviendo a la cadena semántica que establecíamos más arriba entre los significantes agujero y memoria, llegamos a la infancia como el espacio y el tiempo, en el que se inscribe el relato del cronotopo transicional que va construyendo Sanz con sus novelas. La infancia, en este sentido, funciona como un motivo recurrente, sobre el que se vuelve para indagar en esos agujeros de la memoria sobre los que buena parte de las voces narrativas de Sanz vuelven incansablemente para saldar sus cuentas pendientes con el pasado.

Publicada en 2001, Los mejores tiempos es una de las primeras novelas de Marta Sanzy queda, por tanto, todavía distante de los planteamientos que aquí hemos ido señalando en relación con otras de sus novelas más recientes. No obstante, encontramos en ella una primera elaboración del motivo de la infancia en relación con la memoria de la Transición que la autora llegará a desarrollar con plenitud en sus textos posteriores.

Este texto nos interesa solo de forma relativa, ya que el componente central que nos ha servido para articular esta reflexión todavía no ha cobrado forma. Empezando por el hecho de que ese cuerpo femenino que será el protagonista indiscutible en los otros textos que aquí hemos discutido, todavía se escamotea en esta novela tras la perspectiva masculina del narrador. Evidentemente, los intereses narrativos en el momento de la redacción de esta tercera novela que publicaba Marta Sanz hace algo más de quince años, eran otros. No obstante, lo que sí resulta evidente si leemos este texto buscando un retrato del tiempo transicional en consonancia con el que encontraremos en sus textos posteriores, es que, de nuevo, los significantes cuerpo, infancia y Transición van a aparecer, también en este texto, íntimamente ligados entre sí.

Si bien es cierto que la perspectiva de género no la encontramos de forma tan explícita como en otros textos, sí que encontramos en la novela un personaje principal masculino, Mario - un nombre que suena sospechosamente similar al de Marta y cuya masculinidad no está demasiado marcada discursivamente-, que en plena crisis vital se encierra a oscuras en su habitación y trata de reconstruir los pasos que ha ido dando, las decisiones que ha ido tomando y que lo han llevado a un lugar y a una posición ante el mundo que, claramente, no le gusta.

En ese ejercicio de memoria, Mario vuelve sobre su infancia y adolescencia como el escenario de esos mejores tiempos que tienen lugar en el contexto de la Transición. Sin embargo, el relato del pasado transicional que surge de este ejercicio no es, ni mucho menos, nostálgico, sino más bien todo lo contrario. Se narra un tiempo que va desde finales de los años setenta hasta finales de los años ochenta, como el momento en el que el mundo todavía no había cobrado la forma desdibujada que parece tener para el protagonista en su madurez de principios de los 2000. Sin embargo, la narración también dibuja ese pasado como el momento de gestación del desamparo y la insatisfacción que el protagonista de la novela siente hacia el estado de cosas del presente desde el que narra, y que le ha llevado a encerrarse a oscuras en su habitación \#en su agujero\# para concentrase en el hilo de ese recuerdo. Este es, sin duda, uno de los puntos de contacto más significativos de los planteamientos narrativos de Marta Sanz con los de Rafael Chirbes, cuya escritura, en ocasiones, parece resonar de fondo en varios de los textos de nuestra autora.

Infancia y Transición se mezclan, pues, en este texto que adelanta de forma algo críptica muchos de los rasgos que, más de una década después, iban a caracterizar la novelística de Marta Sanz. Aunque no nos extenderemos más en el comentario de este texto, queda pendiente para otro trabajo un análisis del relato de la Transición que van trazando una a una las novelas de Marta Sanz, a partir de la lectura de esta tercera novela, en la que se aborda el tema de una forma más temprana y menos vinculada al contexto de proliferación de los discursos en torno a la Transición y sus usos públicos que ha tenido lugar en el campo literario español en la última década. 


\section{Conclusiones. Hacia una genealogía crítica}

El amplio debate surgido en los últimos años en torno a la Transición y sus relatos puede ser leído, en gran medida, como un problema de transmisión: es decir, un obstáculo en los modos en los que las memorias que quedan al margen de los dispositivos de la memoria más oficial no acaban de ser transmitidos por parte de una generación a las siguientes.

Lo que ponen de relevancia los gestos como el implícito en el texto con el que abríamos esta intervención es que hoy existe, en efecto, un deseo sincero de escuchar esos relatos no transmitidos, o transmitidos a medias. Ese deseo es, en buena medida, un deseo generacional y no parece descabellado pensar que tal vez ese deseo surja del hartazgo y la saturación por sobreexposición a una memoria oficial de la que no han dejado de brotar representaciones, especialmente literarias.

En este sentido, encontramos en los textos de Marta Sanz un potente deseo de transmitir una memoria muy específica: la memoria de los cuerpos femeninos que, tras haber sido silenciada por las tecnologías biopolíticas del franquismo, fue silenciada de nuevo por las tecnologías biopolíticas del neoliberalismo. La memoria que Sanz construye con sus textos es, precisamente, la memoria de ese momento de tránsito -de Transiciónentre una y otra forma de gestión y de control de los cuerpos a través de una serie de discursos que resultan cada vez más sofisticados en sus planteamientos y, probablemente por ello, cada vez más efectivos.

De esa línea que intentábamos dibujar, al inicio de este texto, entre el fragmento de Urraca y el espacio de reflexión que pretendía abrir este trabajo, emerge, más allá de las divagaciones en torno a la imagen del agujero, un trabajo de reflexión sobre la necesidad de reconstruir una suerte de genealogía crítica de la memoria de los cuerpos; una memoria que ejerza de contrapeso efectivo con respecto a una norma de género que, a pesar de los evidentes cambios políticos, sociales y culturales, podemos seguir identificando históricamente con la matriz de una ideología de género que hunde sus raíces en el franquismo.

Hemos ido apuntando a lo largo de este texto hacia una de esas posibles genealogías críticas, por la que podríamos vincular el proyecto narrativo de Marta Sanz con el de Carmen Martín Gaite. Este vínculo tendría su eje en una voluntad explícita que ambos proyectos literarios comparten, aun enunciados en momentos históricos distanciados entre sí en más de tres décadas: la voluntad de desnaturalizar un relato dominante sobre el pasado que se enuncia desde una perspectiva claramente masculina y, en ocasiones, impúdicamente nostálgica.

En este sentido, el gesto que ambas autoras comparten es el de ir desenredando y desenmascarando de la matriz básica de ese relato una serie de discursos que, en ambos casos, tienen que ver con la idea de esa violencia política y cultural de la que hablábamos al inicio, que ha sido ejercida histórica y programáticamente sobre el cuerpo de la mujer a través de una determinada educación sentimental que hunde sus raíces más profundas en la antigua transmutación alegórica entre cuerpo femenino y nación que, con gran rigor, recogía el citado trabajo de Morcillo.

Los textos revisados a lo largo de estas páginas ponen en evidencia hasta qué punto la poética de Marta Sanz busca horadar esa transmutación alegórica el cuerpo femenino ya no solo en un ideal de nación o de belleza, sino de cualquier tipo de ejemplaridad que pueda ser utilizada discursivamente por las estructuras del poder.

\section{Bibliografía}

Ardanaz Yunta, N. (2005). Representaciones de género en el cine español de la transición. En Actes del congrés La Transició de la dictadura franquista a la democracia. Barcelona, 20, 21 i 22 d'octubre(415-426). Barcelona: UAB.

Becerra, D. (2015). Marta Sanz: «El modelo femenino actual es digital, recauchutado y de pubis infantil». Buensalvaje. Recuperado de: http://elasombrario.com/buensalvajees/2015/03/24/marta-sanz-el-modelo-femenino-actuales-digital-recauchutado-serializado-y-de-pubis-infantil/.

Bosch Fiol, E. (1999). Historia de la misoginia. Barcelona: Anthropos. 
Ferrándiz, F. (2014). El pasado bajo tierra. Exhumaciones contemporáneas de la Guerra Civil. Barcelona: Anthropos. Florido Berrocal, J., Martín Cabrera, L., Matos-Martín, E., Robles Valencia, R. (Eds.). (2015). Fuera de la ley. Asedios al fenómeno quinqui en la transición española. Granada: Comares.

Imbert, G. (1982). Elena Francis, un consultorio para la Transición: contribución al estudio de los simulacros de masas. Barcelona: Penísnula.

Labrador, G. (2009). Letras arrebatadas. Poesía y quimica en la transición española. Madrid, Devenir.

Labrador, G. (2015). Poets of the Dead Society. The Cultural History of Francoist Mass-Graves in the Pre-Democratic Poetic Archive. En Legacies of Violence in Contemporary Spain: Exhuming the Past, Understanding the Present. New York: Routledge.

Labrador, G. (2017). Culpables por la literatura. Imaginación politica y contracultura en la transición española (1968-1986). Madrid: Akal.

Martín Gaite, C. (1978). El cuarto de atrás. Madrid: Destino.

Martín Gaite, C. (1987).Usos amorosos de la postguerra española. Barcelona: Anagrama.

Morcillo, A. (2016). En cuerpo y alma. Ser mujer en tiempos de Franco. Madrid: Siglo XXI.

Quaggio, G. (2014). La cultura en transición. Reconciliación y politica cultural en España, 1976-1986. Madrid: Alianza.

Ros Ferrer, V. (2014). "Entrevista a Marta Sanz: Contar la transición, o cómo hablar de la china en el zapato". Kamchatka: revista de análisis cultural, 4, 257-263.

Ros Ferrer, V. (2016). La reconstrucción de la identidad femenina en la Transición española: Daniela Astor y la caja negra de Marta Sanz. En I. Enache, S. Lakhdari, J.Martínez Rubio (Eds.), Identidades inestables. Avatares, evoluciones y teorias de la subjetividad en la narrativa española actual. Paris: Indigo.

Sanz, M. (2013). Daniela Astor y la caja negra. Barcelona: Anagrama.

Sanz, M. (2014). La lección de anatomía [2008].Barcelona: Anagrama.

Segarra, M. (2014). La teoría de los cuerpos agujereados. Madrid: Melusina.

Somolinos, C. (2016). Marta Sanz: cuerpo, escritura e ideología. Ínsula. Revista de letras y ciencias humanas, 834, 20-23.

Touton, I. (2015). Destape del destape: deconstrucción de un poder modelador en la novela Daniela Astor y la caja negra (2013) de Marta Sanz. En C. Colin, P. Peyraga, I. Touton, C. Giménez Navarro, y M.P. Ramouche (Coords.), Imagen y verdad en el mundo hispánico. Construcción/deconstrucción/reconstrucción. París: Orbis Tertus.

Urraca, S. (2016). Hablamos con varias abuelas sobre cómo era su vida sexual. El País, 23 de noviembre. Recuperado de http://elpais.com/elpais/2016/11/21/tentaciones/1479717127_112044.html

Vara, N. (2015). Lecciones de yo: autobiografía, ficción y sujeto ético en Marta Sanz. RECIAL. Revista del Centro de Investigaciones de la Facultad de Filosofia y Humanidades, Areas Letras, 7.

\section{Notas}

1 Hace poco tuve la ocasión de escuchar una conferencia en la que la hispanista británica Jo Labanyi proponía un análisis de la Regenta desde lo que los estudios culturales han denominado the affect theory. La conferencia llevaba por título "Los afectos negativos en La Regenta", y en ella Labanyi abría su intervención explicando por qué le parecía imprescindible proponer una lectura tanto de la obra de Clarín como de la Madame Bovary de Flaubert desde una perspectiva que escapara al clásico enfoque psicoanalítico en relación con la figura de la histérica que se suele aplicar todavía hoy desde la crítica, tanto para interpretar como para transmitir estas obras en el contexto escolar. El principal motivo por el que Labanyi rechazaba este enfoque psicoanalítico fue el mismo al que me acabo de referir en el texto. Puede escucharse la conferencia completa en el siguiente enlace: https://www.youtube.com/watch?v=pKvm9ycqB5g\&t=4221s.

2 "En español, agujero viene de aguja, del latín aucucula, diminutivo de acus, que significaba “aguja”. Hasta aquí la historia no es muy sugerente, pero si nos remontamos más en el tiempo, averiguamos que acus procede de la raíz indoeuropea ${ }^{*} a k$, de la que derivan términos connotando lo agudo y afilado; además, esta raíz está en el origen de la palabra inglesa heaven (cielo). En inglés, el término equivalente a agujero, hole, deriva a su vez de la raíz indoeuropea *kel, que da el latín cella (celda; más tarde, también la célula), relacionado con celare (celar, ocultar) -y veremos que el agujero suele estar en 
relación con lo secreto y lo sagrado-. Más interesante aún, de esta misma raíz procede también hell, "infierno": dos de los espacios imaginarios más relevantes en religiones y mitologías varias, cielo e infierno, se relacionan en inglés con el agujero, lo cual refleja la vocación paradójica y contradictoria de esta figura" (Segarra, 2014: 11)

3 "Otra etimología interesante es la del trou francés, que viene del latín popular traucum (al igual que el catalán trau). En sus orígenes, este término designaba una abertura que atraviesa el cuerpo, y más tarde una herida profunda, además de referirse a una cavidad en la que se refugia un animal. Muy pronto, en la Edad Media, adquirió un significado sexual, designando el sexo de la mujer, así como otros orificios anatómicos de reputación dudosa y placer asegurado" (Segarra, 2014:11).

4 Entre otros usos, uno muy interesante es el de trou de mémoire, el agujero que se produce en la memoria cuando nos quedamos en blanco y tenemos un nombre en la punta de la lengua y no logramos pronunciarlo. La imagen de la memoria como una masa sólida en la que el despiste, o la edad, va cavando agujeros, es tanto más inquietante cuanto más gráfica (Segarra, 2014: 12).

5 Este texto recoge la intervención de Sánchez León en uno de los primeros encuentros científicos dedicado a la recuperación de la memoria histórica de la represión durante el franquismo celebrado en el año 2002 que, al año siguiente, sería publicada en el contexto de un libro colectivo titulado La memoria de los olvidados: un debate sobre el silencio de la represión franquista (2003).

6 La argumentación de Sánchez León es mucho más amplia y está documentada con datos estadísticos: ofrecemos aquí únicamente su tesis principal. Es importante señalar que el texto de Sánchez León es muy temprano, en este sentido. En los últimos años, la bibliografía sobre este tema ha aumentado considerablemente (Labrador, 2009 y 2017; Florido Berrocal, Martín Cabrera, Matos-Martín y Robles Valencia (2015); etc.).

7 El trabajo en torno a la fosa común como dispositivo para pensar sobre la emergencia de la memoria histórica en España ha sido trabajada desde el campo de la antropología por Francisco Ferrandiz (2014). Sobre sus trabajos, Germán Labrador (2015) ha propuesto su aplicación a la producción cultural surgida en este contexto desde el campo de los estudios culturales.

8 De hecho, esta transmutación se puede observar con enorme claridad con el famoso desnudo de Marisol para la revista Intervíu en abril de 1976, que Marta Sanz recoge, muy significativamente, hacia el final de su Daniela Astor y la caja negra en forma de écfrasis: el cuerpo desnudo de Marisol como alegoría de la joven y frágil democracia. La imagen tiene dos caras: la del objeto Marisol que es representada alegóricamente por y para la mirada masculina y la del sujeto Marisol que toma la acción de desnudarse ante la cámara (Ros, 2016).

9 Un buen ejemplo de esto eran los famosos consultorios sentimentales que, sorprendentemente, existieron hasta la década de los 80. El sociólogo francés Gérard Imbert es autor de un interesante y muy temprano trabajo al respecto (Imbert, 1982). En su ensayo Usos amorosos de la posguerra española, Carmen Martín Gaite da muchas de las claves de esa educación sentimental, algunas de ellas también en relación con el funcionamiento de los consultorios sentimentales.

10 Morcillo señala que la "subversiva" influencia de los medios de comunicación a partir de este momento tuvo un tan importante en la configuración de la cultura y el panorama político que, en países como España, llegó a ser similar a la de los Ministerios de Estado. Sin ir más lejos, el Ministerio de Información y Turismo creado y dirigido por Fraga en su primera etapa, constituye un perfecto ejemplo de hasta qué punto se empieza a dar, ya en la década de los sesenta, una asimilación por parte del Estado de los discursos economicistas (Quaggio, 2014). Evidentemente Morcillo entiende la influencia de la imagen de la mujer en los medios de comunicación como subversiva sólo en tanto que empezaba a desmarcarse de la moral nacionalcatólica del régimen, sin entrar todavía a valorar los efectos del discurso capitalista que empieza a introducir en España la cultura del desarrollismo, que es justo el punto de entrada de los textos de Marta Sanz.

11 Aunque algunos piensen que fue Freud quien inventó el latinismo 'vagina dentata' para referirse al miedo ancestral que el sexo femenino infunde a los hombres, en realidad el origen del término se halla en la antropología. En su Historia de la vagina, Catherine Blackledge describe la abundante presencia del motivo de la vagina armada de dientes en las culturas antiguas de todo el mundo [...]. 'Se abre la caja de Pandora' es el título del capítulo que le dedica la historiadora, pues esta caja o ánfora mitológica, que al ser abierta por la diosa griega originó todos los males de los hombres, se ha comparado también con el sexo femenino. (Segarra, 2014: 63).

12 La asignación del valor de "potencia demográfica" al cuerpo femenino es común en los regímenes totalitarios. Esta idea es desarrollada con mayor detalle en Bosch Fiol, Esperanza, Historia de la misoginia, Barcelona, Anthropos, 1999.

13 Entre 1977 y 1978 se aprobaron una serie de leyes por las que se despenalizaba el adulterio, el amancebamiento y el uso de métodos anticonceptivos. El divorcio se legalizó en 1981. El aborto no se despenalizó hasta 1983, cuando el gobierno socialista aprobó una ley que no entraría en vigor hasta 1985 - una ley por la que se suprimía el castigo de cárcel para la mujer que abortara bajo los famosos 3 supuestos (peligro para la embarazada, violación, tara física o psíquica del feto).

14 Especialmente interesante, en este sentido, resultaría el análisis del personaje de Luis Bagur en relación con el mito de Pigmalión que el propio texto propone como clave interpretativa del mismo. El mito de Pigmalión será, además, un motivo que encontraremos repetido en los discursos más críticos que, desde el feminismo, empiezan a surgir desde finales 
Olivar, junio 2018, vol. $18, \mathrm{n}^{\circ} 27$, e024. ISSN 1852-4478

de los años sesenta. Un buen ejemplo lo constituye el mediometraje de Cecilia Bartolomé Margarita y el lobo (1968) o incluso el relato de Manuel Vázquez Montalbán que da título al volumen Pigmalión y otros relatos (1987).

15 En la entrevista de David Becerra para Buensalvaje. 